\title{
LETTERS
}

\section{Increased rate of early smoking in children and adolescents with attention- deficit/hyperactivity disorder}

I applaud the article by Thombs and colleagues ${ }^{1}$ on behavioural interventions for the prevention and treatment of cigarette smoking among school-aged children.

The article recommends that prevention and treatment strategies exclude patients who have cognitive deficits, mental or physical health problems and a history of alcohol or substance abuse.

Although this approach is to be commended as an important public health initiative, it may not be addressing underlying problems in subgroups of individuals who started smoking at an early age and are resistant to this intervention.

Recent research shows a high prevalence of early smoking in children with attentiondeficit/hyperactivity disorder (ADHD). ${ }^{2}$ Imaging studies examining the impact of nicotine on those who start smoking at an early age and have ADHD have shown a more adverse effect on prefrontal ischemia than for those smokers who do not have ADHD. ${ }^{3}$ Treatment with stimulants reduces objective measures of cigarette smoking and emotional lability in smokers with ADHD. ${ }^{4}$

Importantly, early cigarette smoking may mask the detection of ADHD because of the improvement in focus and mood stability secondary to the stimulant effects of nicotine effects on ADHD mediated by dopamine release. ${ }^{5}$ Therefore, any suggested exclusion screen for cognitive deficit in this study may not identify individuals who smoke and have ADHD.

It may be important to consider a more detailed history of ADHD in patients who fail the behavioural intervention that is outlined in the article.

In 2013, a study conducted in Europe showed that stimulant treatment for ADHD reduces the liability to addictive behaviours including tobacco dependence toward that of their non-ADHD peer group. ${ }^{6}$

\section{Laurence Jerome MB ChB MSc}

Adjunct Professor, Division of Child and

Adolescent Psychiatry, Western University, London, Ont.
- Cite as: CMAJ 2017 May 29;189:E755. doi: $10.1503 / \mathrm{cmaj} .733013$

\section{References}

1. Canadian Task Force on Preventive Health Care. Recommendations on behavioral interventions for the prevention and treatment of cigarette smoking among school-aged children and youth. CMAJ 2017;189:E310-6.

2. Kollins SH, McClernon J, Fuemmeler BF. Association between smoking and attention-deficit/ hyperactivity disorder symptoms in a populationbased sample of young adults. Arch Gen Psychiatry 2005;62:1142-7.

3. Gehricke J-G, Polzonetti C, Caburian C, et al. Prefrontal hemodynamic changes during cigarette smoking in young adult smokers with and without ADHD. Pharmacol Biochem Behav 2013;112:78-81.

4. Gehricke J-G, Hong N, Wigal TL, et al. ADHD medication reduces cotinine levels and withdrawal in smokers with ADHD. Pharmacol Biochem Behav 2011;98:485-91.

5. Gehricke J-G, Hong N, Whalen CK, et al. Effects of transdermal nicotine on symptoms, moods, and cardiovascular activity in the everyday lives of smokers and nonsmokers with attention-deficit/ hyperactivity disorder. Psychol Addict Behav 2009; 23:644-55.

6. Groenman AP, Oosterlaan J, Rommelse NN, et al. Stimulant treatment for attention deficit hyperactivity disorder and the risk of developing substance use disorder. Br J Psychiatry 2013;203:112-9.

Competing interests: None declared. 